\title{
Rhinoscleroma with exophthalmos: a case report
}

\author{
JANE R. LUBIN, ${ }^{1}$ SULAYMAN E. JALLOW, ${ }^{1}$ WILLIAM R. WILSON, \\ ARTHUR S. GROVE, ${ }^{1}$ AND DANIEL M. ALBERT ${ }^{1}$ \\ From the Harvard Medical School, Massachusetts Eye and Ear Infirmary, \\ ${ }^{1}$ Department of Ophthalmology, and 'Department of Otolaryngology, Boston, \\ Massachusetts, USA
}

SUMMARY This is a report of a 20 -year-old Nigerian man with a 15 -year history of exophthalmos and nasal blockage caused by rhinoscleroma. The diagnosis was made by histopathological examination of a biopsy specimen taken from the nasal passages. Despite protracted antibiotic therapy the patient experienced recurrent exophthalmos. Computerised axial tomography and sinus films showed the lesion to have invaded through the sinus passage into the orbit. Further histopathological examination of tissue removed at the time of surgical decompression also revealed rhinoscleroma. This appears to be the third report of rhinoscleromatous spread to the orbit.

Rhinoscleroma is a chronic granulomatous disease of the nasal passages and respiratory tract, originally described by the Viennese dermatologist von Hebra in $1870 .{ }^{1}$ The lesion was originally described as malignant because of its tendency to invade surrounding tissues. In 1882 von Frisch ${ }^{2}$ identified a Gram-negative, encapsulated bacillus which could be isolated from the nasal lesions of patients with scleroma. Similar organisms were reported in up to $98 \%$ of patients with the lesion, and could not be found in normal controls or in patients with other nasal cavity diseases. ${ }^{34}$ Koch's postulates were not fulfilled until 1961, when Steffen and Smith injected the bacillus into the nasal cavity and intracranially in mice and produced a pneumonia which in some cases became chronic. The pulmonary lesions produced closely resembled the chronic granulomatous structure of scleroma, with predominance of plasma cells and lymphocytes, Russell bodies, and large, vacuolated macrophages (Mikulicz cells). ${ }^{5}$

Rhinoscleroma is rarely seen in the United States. In 1942, 102 cases had been reported there, only 16 of which had occurred in native-born Americans. ${ }^{6}$ After the second world war with increased travel and immigration rhinoscleroma has been seen more commonly in this country, though it remains a rare disease. It is endemic in parts of Asia, Africa, and South and Central America. It is particularly common in Egypt and Indonesia. Rhinoscleroma is now

Correspondence to Daniel M. Albert, MD, Howe Laboratory of Ophthalmology, Massachusetts Eye and Ear Infirmary, 243 Charles Street, Boston, MA 02114, USA. being seen with increasing frequency in south-east Europe, Poland, Hungary, south-west Russia, and in the south-western United States among Mexican populations. ${ }^{7}$ Endemic areas are thought to have common environmental factors favourable to the spread of the causative agent: poor nutrition, poor hygiene, and overcrowding in the homes. ${ }^{8}{ }^{9}$ Close personal contact is thought to be necessary for spread of the disease. The vector may be an insect, but this has never been shown.

The process always arises in the nasal passages and often affects the nose, pharynx, and larynx. Recently Holinger et al. ${ }^{10}$ reported 11 cases of rhinoscleroma with varying degrees of involvement of the lower respiratory tract, including trachea and bronchi. Quevedo, in his large Guatemalan study, described scleromatous infiltration of the Eustachian tube and middle ear cavity. ${ }^{11}$ Mossallam and Attia ${ }^{12}$ reported a primarily unilateral scleroma of the right maxillary antrum. Hara ${ }^{13}$ reported intracranial spread of the lesion in the orbit. Shaw and Martin ${ }^{7}$ described a case of bilateral orbital spread of rhinoscleroma showing extension through the nasolacrimal duct and presenting variably as obstruction and/or infection of the lacrimal passages. Spread to the cervical lymph nodes has also been reported. ${ }^{14}$

\section{Case report}

A 20-year-old black male was referred from Nigeria in November 1977 for evaluation and treatment of recurrent right exophthalmos associated with pain 
since the age of 6 years. In 1964, at the age of 7 , the patient had nasal blockage and bilateral proptosis. Surgery was performed on both orbits with incisions below the brows. Examination of biopsy material resulted only in a tissue diagnosis of 'nonspecific inflammation'. The process became quiescent and did not progress for 10 years. In 1974 the patient had a recurrence of right exophthalmos associated with diplopia in upward gaze. Once again orbital exploration revealed 'nonspecific inflammation'. In August 1977 the right orbit was reexplored through an incision below the brow. Postoperatively the right upper lid was almost completely ptotic. In November 1977 nasal blockage recurred, and nasal biopsy produced a histological diagnosis of rhinoscleroma, with granulomatous inflammation similar to that seen in the orbit.

The patient gives no history of systemic illness and no history of strabismus prior to the development of this inflammatory tumour. There is no family history of eye disease. He had no evidence of cardiac or renal dysfunction.

After diagnosis of rhinoscleroma he was placed on $1 \mathrm{~g}$ of tetracycline per day for 6 weeks without improvement.

On presentation to the Massachusetts Eye and Ear Infirmary the patient had $12 \mathrm{~mm}$ right exophthalmos (Fig. 1). The right globe was displaced downward and laterally; there was marked decrease in orbital resilience. Upgaze was markedly restricted. No palpebral fissure was noted in the right eye; levator function was $4.5 \mathrm{~mm}$. Palpebral fissure in the left eye measured $8.5 \mathrm{~mm}$; levator function was $16 \mathrm{~mm}$. Visual acuity was $6 / 6(20 / 20)$ OU. A firm, painless mass could be palpated behind the right ear.

Orbital $x$-rays revealed increased soft tissue density in the right orbit, with a normal optic foramen. Sinus films showed a large, polymorphous soft-tissue density in the right maxillary sinus. There was slight irregularity and enlargement of the middle turbinate posteriorly in the right side of the nasal fossa laterally. An increased density was seen in the anterior portion of the right sphenoid sinus, while its medial wall showed sclerosis and bulging. The left maxillary sinus showed minimal mucosal thickening inferiorly but was otherwise normal.

Computerised axial tomography revealed the presence of an area of high absorption located behind and superior to the right globe, causing downward gaze and forward displacement. No evidence of bony destruction was noted (Fig. 2). Orbital ultrasound confirmed this finding, showing a tumour above the right globe, extrinsic to the muscle cone, extending posteriorly along the roof of the orbit and laterally along the orbital wall. No internal echoes were seen, confirming a homogeneous solid tumour.

The patient was treated with $3 \mathrm{~g}$ of ampicillin per day for 6 weeks, again without significant improvement. In July 1978 the patient underwent a lateral orbitotomy and exploration of the right orbit, with excision of the tumour and orbital decompression. At operation a firm, nodular, and deeply adherent tumour was found extending along the lateral surface of the orbit and into the muscle cone. Fragments were removed, but arterial bleeding supervened, and the procedure was terminated. Postoperatively visual acuity in the right eye was $6 / 9(20 / 30)$, and the upper lid was still ptotic.

Histopathological examination of tissue removed

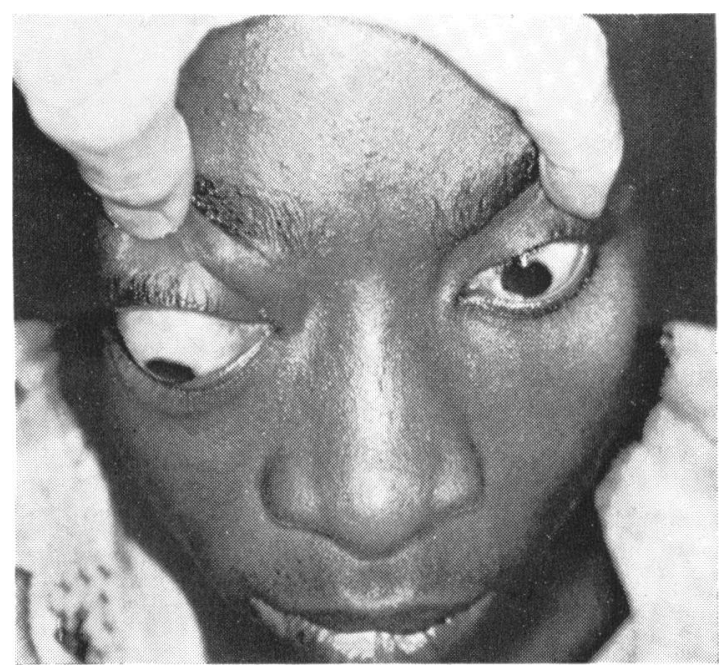

Fig. 1 Patient photographed from above showing $12 \mathrm{~mm}$ right exophthalmos.

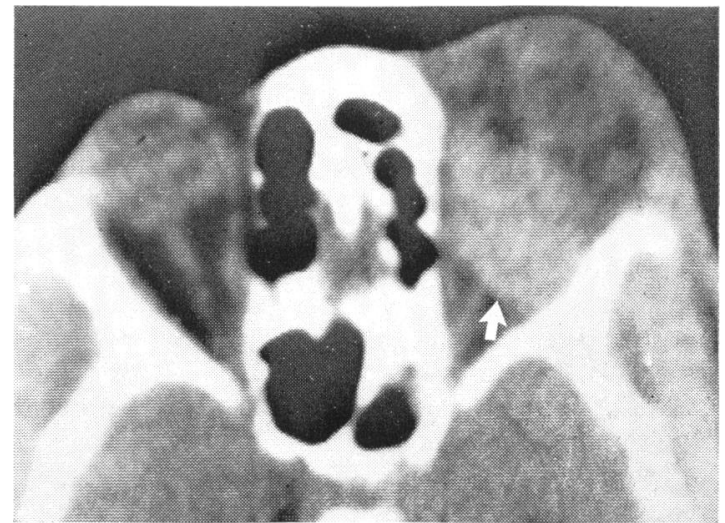

Fig. 2 Computerised axial tomography of the orbits showing lesion as an area of high absorption behind the right globe (arrow). 
Fig. 3 Low power: sclerotic bands of connective tissue which encircle small areas of dense inflammatory cell infiltrate. (Haematoxylin and eosin, $\times 25$ ).

High power (inset): Mikulicz cells $(H$ and $E, \times 100)$.

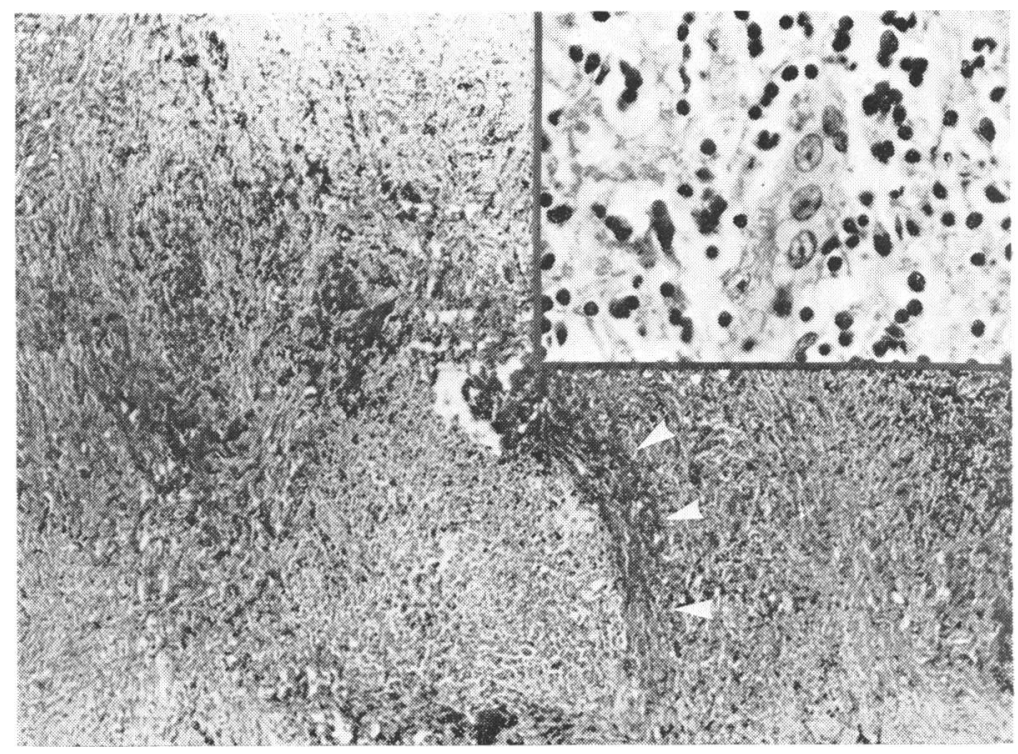

at the time of orbital exploration revealed tissue with discrete nodules of granulomatous inflammation. The bulk of the specimen was composed of sclerotic bands of connective tissue which encircled small areas of dense inflammatory cell infiltrate. The inflammatory cells were mostly a dense lymphocytic cell infiltrate with many plasma cells and hyaline Russell bodies. Large, foamy, vacuolated histiocytes were also seen (Fig. 3). No organisms were found within these cells with Brown-Brenn or Giemsa stains.

\section{Discussion}

Cases of rhinoscleroma with invasion into the orbits are rare. Only 3 cases exist in the otolaryngological literature, ${ }^{2} 715$ and none has been reported in ophthalmic journals. The lesion usually starts as small granulomas on the nasal septum or lower turbinates, which eventually coalesce to form obstructing masses in the air passages of the nose, pharynx, larynx, and downwards to the trachea and bronchi, often impairing swallowing and requiring tracheostomy. Infiltration upwards through the sinuses and lacrimal apparatus is unusual but is being reported with increasing frequency. ${ }^{716}$ Relentless progression of the process, while it does not invade bone itself, causes pressure atrophy of facial bones and may invade the base of the skull and proceed to the orbits, causing serious complications like meningitis and blindness by pressure on the optic nerve. Infection and haemorrhage are usually the cause of death in fatal cases of this sclerotic process.

The first case of orbital involvement by rhino- scleroma was reported by Hara ${ }^{13} \mathrm{He}$ postulated that the route of extension was either through the ethmoidal-orbital plate or by way of the nasolacrimal tract into the orbit. Shaw and Martin ${ }^{7}$ reported a case in their series which showed invasion of both orbits and the skull base. with pressure atrophy of adjacent bone producing proptosis and blindness, with intractible pain. This progression may lead to cranial nerve palsies, as in our case, and meningitis is a possibility. In our case the route of spread was via the sinuses, as shown on orbital $x$-rays and computerised axial tomography scan. Surgical exploration of the sinuses also revealed a grossly sclerotic process; no biopsy was taken.

Hsiung-Hsiang ${ }^{15}$ reported a similar case in 1958. The mode of extension in that case was also through the sinuses. The possibility of intracranial spread of infection is emphasised in these cases because of difficulty in eradicating the organism, even with bactericidal drugs. Organisms within the macrophages seem to be protected from the host's immune system and remain viable even through prolonged courses of antibiotic therapy.

Rhinoscleroma passes clinically through various stages. It initially presents as mucosal congestion, which proceeds to suppurative rhinitis. The disease then passes through stages of chronic rhinitis, atrophic rhinitis, and finally to chronic granuloma, and then the sclerotic stage.

As the granulomas fibrose, they become less recognisable as specific for rhinoscleroma, and some of the characteristic features disappear. The lesion becomes a fibrotic, sclerotic scar, which contracts and deforms the normal anatomy. Most of 
our specimen showed this sclerotic change, but also younger areas of the characteristic inflammatory cell infiltrate were present.

The Mikulicz cells ${ }^{17}$ are characteristic of rhinoscleroma but not pathognomonic. They are also seen in leprosy and bubonic plague and are thought to represent the cells' nonspecific response to toxins produced by the causative organism. Large numbers of the rhinoscleroma bacillus, Klebsiella rhinoscleromatis, can sometimes be found within the Mikulicz cells. They stain faintly with haematoxylin and eosin, but may require Gram's stain or Giemsa to be seen. No bacilli were seen in our specimen with special stains, probably owing to prolonged administration of ampicillin. It is thought that the difficulty in eradicating the organisms stems from their being sequestered within the histiocytes and protected from the immune system.

The long-term management of this patient poses a real problem. So long as visual acuity remains 20/20 little should be done surgically. Perhaps a trial of corticosteroid therapy would be appropriate to retard exacerbations of the inflammatory response. Patients must also be carefully watched for signs of meningeal involvement. Protracted courses of antibiotics may be necessary. With regard to vision, the real destructive process is not the active inflammatory disease but the sclerotic, contractive changes as the lesion progresses. They threaten the optic nerve by cutting off the blood supply and distorting orbital and muscular anatomy. There is no effective treatment for this phase of the disease.

It is unfortunate that there is no mention of orbital involvement in rhinoscleroma in the ophthal- mic literature. We believe that ophthalmologists should be aware of the disease and the problems of its management.

\section{References}

1 von Hebra F. Ueber ein eigen theumlicher Neugeblide an der Nase. Wien Med Wochenschnr 1870; 20: 1-17.

2 von Frisch A. Zur Aetiologie des Rhinoscleroma. Wien Med Wochenschr 1882; 32: 969 -73.

3 Sinha A, Pandhi SC, Prakash OM. Aetiopathogenesis: scleroma. J Laryngol Otol 1969; 83: 133-9.

4 Levine MG, Hoyt RE, Peter JE. Scleroma: an etiological study. J Clin Invest 1974; 26: 281-6.

5 Steffen TN, Smith IM. Scleroma: Klebsiella rhinoscleromatis and its effect on mice. Ann Otol Rhinol Laryngol 1961; 70: 281-6.

6 Cunning DS, Guerry D. Scleroma. Arch Otolaryngol 1942; 36: 662-78.

7 Shaw HJ, Martin H. Rhinoscleroma: A clinical perspective. J Laryngol Otol 1961; 75: 1011-39.

8 Oomen HAPC. The clinical course of rhinoscleroma. Doc Med Geogr Trop (Amst) 1952; 4: 124-33.

9 El-Mofty A. A histological examination of scleroma. Ann Otol 1962; 71: 377-81.

10 Holinger PH, Gelman HK, Wofe CK. Rhinoscleroma of the lower respiratory tract. Laryngoscope 1977; 87: 1-9.

11 Quevedo J. Scleroma in Guatemala. Ann Oto! Rhinol Laryngol 1949; 58: 613-45.

12 Mossallam I, Attia DM (Title not available). J Egypt Med Assoc 1956; 39: 512-21.

13 Hara HJ. Scleroma. Laryngoscope 1957; 67: 695-708.

14 Badrawy R, El-Shennawy M. Affection of the cervical lymph nodes in rhinoscleroma. J Laryngol Otol 1969; 85: $269-74$.

15 Hsiung-Hsiang Y. (Title noc available). Chin Med J 1958; 77: 262-81.

16 Badrawy R. Dacryoscleroma (scleroma of the lacrymal passages). Ann Otol Rhinol Laryngol 1962; 71: 247-54.

17 Mikulicz J. Ueber das Rhinosclerom. Arch Klin Chir $1877 ; 20$ : $485-8$. 